\title{
Development of ecologically safe technology of recycling of industrial waste in the production of modified non-autoclave aerated concrete
}

\author{
Evgeniya Tkach $^{1, *}$ \\ ${ }^{1}$ Moscow State University of Civil Engineering, Yaroslavskoe sh. 26, 129337 Moscow, Russia
}

\begin{abstract}
The results of environmental monitoring for environmental security within the framework of territorial administration of the Central Federal district of the Russian Federation showed the necessity of developing a new ecological mechanism for rational control of the process of recycling of technogenic wastes. It is established that at increase of industrial production and the growth and accumulation of industrial waste and increases the negative impact on the environment. Determined that the production of phosphorus mineral fertilizers in Russia as a whole is formed 25 million tons per year of phosphogypsum, and utilized only a tenth. In Russia on distilleries waste DDGS is 9-14 million tons per year, not utilized - about 1 million tons. In Russia milk manufacture gives rise to waste of whey in an amount of about 6 million tons per year. Warehousing, industrial waste dumps occupy thousands of hectares. They are washed into sewers, groundwater, reservoirs, result in the earth, causing serious ecological damage to the environment. This requires the disposal of such waste. The most promising method of disposal is considered as the placement of industrial waste in the production of construction materials, particularly aerated concrete products.
\end{abstract}

\section{Introduction}

When the analysis and synthesis of contemporary research and experience in the production of cellular concrete is determined that it is necessary to continue the search for new environmental and technical ways to expand the raw material base of their production. Moreover, increased production of cellular concrete by 2020, and environmental degradation due to the growth of volumes of industrial waste requires the adoption of new solutions. Best way disposal is a disposal in the production of effective and environmentally-friendly porous concrete. This is confirmed by the analysis of existing studies. However, if environmental and technical analysis found that existing technology of production of cellular concrete have a number of disadvantages that affect environmental safety. These include: energy and explosive pressure production with a high pressure and temperature, the possibility of explosion by release of hydrogen from the concrete mass after swelling [1-2]. A set of problems associated with the construction technical properties

* Corresponding author: ev tkach@,mail.ru 
of concrete mixtures arises: the excess of mixing water during the injection molding technology is that the increase of the set of structural strength and manufacturing process, the presence of waste after cutting and cutting crusts of the problem of interrelation between the viscosity of the system and the limiting shear stress of concrete mixtures [3-4].

\section{Problem statement}

The goal of the presented research is to develop two-stage environmental mechanism for large-scale disposal of industrial wastes in the production of concrete products with improved physico-technical properties. It is established that two-stage ecological mechanism of large-scale disposal of industrial wastes in the production of concrete products includes: environmental assessment of industrial waste; the definition of the full life cycle of products based on industrial waste; the two-stage method of waste disposal while obtaining complex organic-mineral modifier and modified non-autoclave gasconcrete products; environmental assessment of production technologies of concrete products based on industrial waste; the total ecological rating of technogenic wastes, technology of production and operation of concrete products based on industrial waste throughout the entire life cycle of products. Based on a proposed block diagram and the theoretical basis has been developed ecologically safe technology of production of structural and heat-insulating modified aerated concrete. It includes several main stages of technological process: preparation of raw materials, preparation of concrete mixture, molding; heat treatment.

The method of disposal of anthropogenic wastes comprises of the production technology of modified non-autoclave aerated concrete products, operating in a closed cycle and includes the main stages: pre-autoclaved aerated concrete mixer in the mixing of the batched by weight components: sand, cement with water and phosphogypsum for 3-5 min.; cooking in the mixer slurry of aluminum in an aqueous solution of a surfactant (organic modifier) to remove paraffin from the surface of the aluminum powder; mixing the autoclaved aerated concrete mixer is obtained a slurry of aluminum in an aqueous solution of a modifier with the basic components of aerated concrete mixture for 1-3 minutes; pouring the thoroughly mixed concrete of a mixture forms when the air temperature in the shop $+18-20^{\circ} \mathrm{C}$; the swelling of the concrete mass in a fixed form (9) within 30-50 min.; cut layer and cutting the array in blocks of special cutting machine with metal strings, reciprocating and rotational motion, grinding, cut "salmon", i.e., extending beyond the dimensions of the array in its upper part, and the return of this waste in the autoclaved aerated concrete mixer for mixing with the main components of the mixture; heat treatment of the cut blocks in the chamber with insulating cover. Cap allows to reduce energy consumption compared to traditional thermal processing in autoclaves. Curing takes place within 5-6 hours. The use of thermal insulation cap allows to protect the aerated concrete products from drafts and heat loss, which enables to obtain a stable quality of the blocks; stacking, packing of ready-made blocks and sent to the warehouse of finished products; defective product sent to the grinding with the subsequent return to mixing in the autoclaved aerated concrete mixer with the components of the mixture.

On the ecological safety of the environment will influence the quality of the structure and the quantitative values of the indicators of construction and technical properties [5-7]. The definition of such properties of the modified non-autoclaved aerated concrete based on industrial wastes has allowed to establish the suitability standard, i.e. the possibility of their use in construction. The quality of concrete structures depends not only its strength, but also such important characteristics as environmental safety, high density, thermal insulation, water absorption, capillary leak, and others [8-10]. 


\section{Results and discussion}

The results of x-ray diffraction and microstructural analyses found that the use of modified aerated concrete based on industrial wastes will provide ecological security by improving the uniformity, structure hardening, the cement consumption and energy production and home heating while reducing the release of heat into the atmosphere. To conduct microstructural analysis of the samples obtained modified concrete was used to install an electronic raster microscope-microprobe FEI Quanta 200 SEM(fig.1-2).

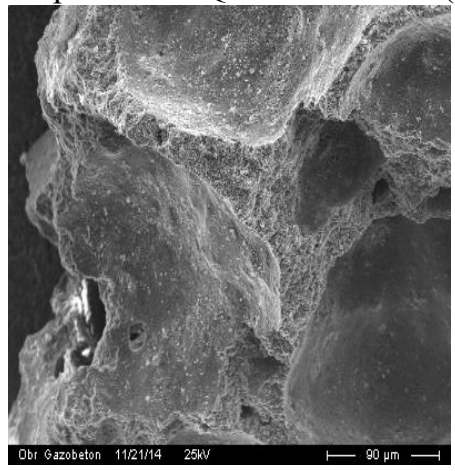

Fig. 1. Structure of modified non-autoclave aerated concrete: macrostructure.

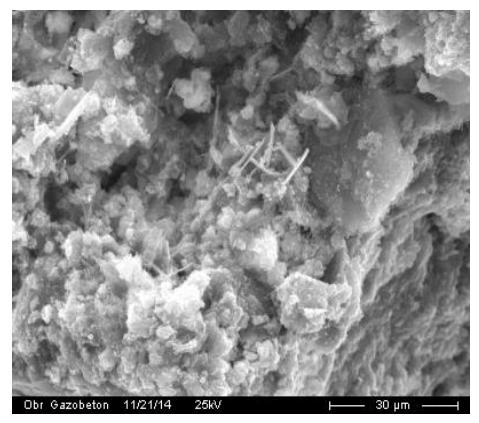

Fig. 2. Structure of modified non-autoclave aerated concrete: microstructure.

The types and distribution of the pore diameters in the control composition and a modified concrete made of the proposed technology are shown in table 1.

Table 1. Porosity of modified aerated concrete.

\begin{tabular}{|l|c|c|}
\hline \multicolumn{1}{|c|}{ The types of pores } & The pore size, cm & Share in total porosity, $\%$ \\
\hline \multicolumn{3}{|c|}{ The control (traditional concrete) } \\
\hline Gel & $1 \cdot 10^{-6}-5 \cdot 10^{-6}$ & $10-15$ \\
\hline Capillary & $8 \cdot 10^{-5}-2 \cdot 10^{-4}$ & $15-25$ \\
\hline Wire mesh & $10^{-4}-(0.12-0.15)$ & $60-75$ \\
\hline \multicolumn{3}{|c|}{ Modified aerated concrete } \\
\hline Gel & $1 \cdot 10^{-6}-5 \cdot 10^{-6}$ & $7-9$ \\
\hline Capillary & $8 \cdot 10^{-5}-2 \cdot 10^{-4}$ & $10-15$ \\
\hline
\end{tabular}




\section{Wire mesh}

$10^{-4}-(0.05-0.08)$

$76-83$

To confirm the conformity of the modified non-autoclaved aerated concrete based on industrial wastes it is necessary to conduct not only the microstructural, but also $\mathrm{x}$-ray studies. The results of x-ray diffraction studies are presented in figure 3 and 4.

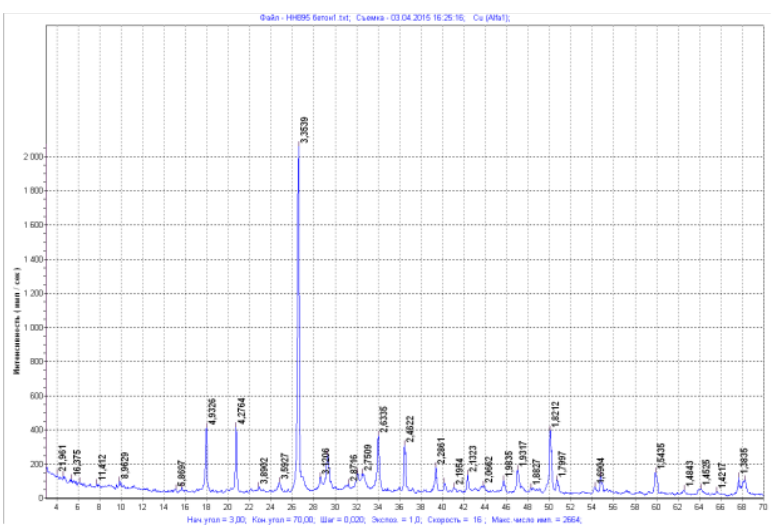

Fig. 3. Diffraction patterns of aerated concrete of the control composition ( traditional).

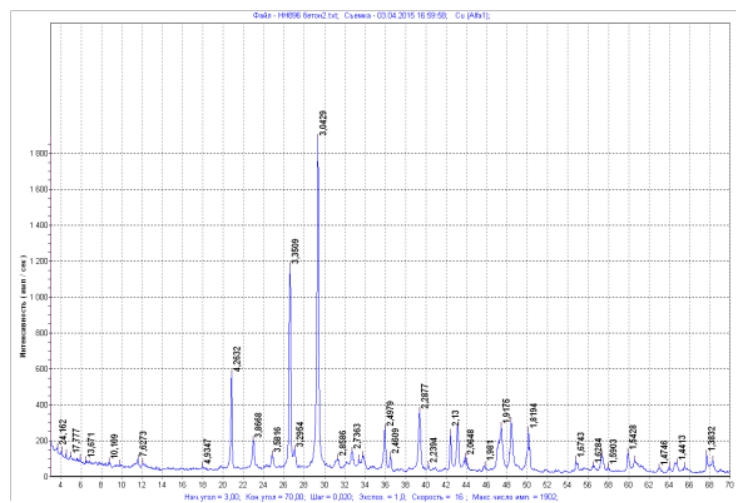

Fig. 4. Diffraction patterns of aerated concrete of the modified composition.

$\mathrm{X}$-ray analysis in figure 1, allowed the identification of the following compounds: alit $\mathrm{C}_{3} \mathrm{~S}$ with the interplanar distance with the peak $\mathrm{d}=(3.03 ; 2.78 ; 2.75 ; 2.61 ; 2.18 ; 1.76 ; 1.49$ etc.) $10^{-10} \mathrm{~m}$. At the peak $\mathrm{d}=1.76$ assesses the degree of hydration of cement. Modified aerated concrete it is equal to $91 \%$,and it assesses the aerated concrete control or traditional composition- $67 \%$.

Therefore, the first higher strength and other properties better than the second: $\mathrm{C}_{3} \mathrm{~A}$ with the peak $\mathrm{d}=(4.23 ; 4.08 ; 2.05 ; 1.91) \cdot 10^{-10} \mathrm{~m}$; , Belit $\beta_{\mathrm{L}}-\mathrm{C}_{2} \mathrm{~S}$ with the peak $\mathrm{d}=(2.748 ; 2.609$; $2.189 ; 2.047 ; 1.98 ; 1.696) \cdot 10^{-10} \mathrm{~m} ; \mathrm{C}_{4} \mathrm{AF}$ with the peak $\mathrm{d}=(7.32 ; 2.67 ; 2.04$; $1.92 ; 1.81 ; 1.39) 10^{-10} \mathrm{~m}$; quartz: $\beta-\mathrm{SiO}_{2}$ with the peak $\mathrm{d}=(4.26 ; 3.35 ; 1.82 ; 1.54) \cdot 10^{-10} \mathrm{~m}$. This suggests that quartz sand in a modified aerated concrete became part of the matrix of interporous partitions, reinforcing them and reduced shrinkage, natural gypsum $\mathrm{CaSO}_{4} \cdot 2 \mathrm{H}_{2} \mathrm{O}$ with the peak $\mathrm{d}=(7.56 ; 4.26 ; 1.99 ; 1.66) \cdot 10^{-10} \mathrm{~m}$, calcite $\mathrm{CaCO}_{3}$ with the peak $\mathrm{d}=(3.828 ; 3.04 . .3 .06 ; 2.511 ; 2.301 ; 1.88) \cdot 10^{-10} \mathrm{~m} . \mathrm{CSH}(\mathrm{I})$ the partially crystallized calcium silicate hydrate with the peak $\mathrm{d}=(12.5 ; 3.07 ; 2.8 ; 1.83) \cdot 10^{-10} \mathrm{~m}, \mathrm{CSH}(\mathrm{II})$ with the peak $\mathrm{d}=(9.8 ; 3.07 ; 2.8 ; 2.0 ; 1.83 ; 1.56) \cdot 10^{-10} \mathrm{~m} ., \mathrm{Ca}(\mathrm{OH})_{2}$ with the peak $\mathrm{d}=(4.93 ; 3.11$; $2.63 ; 1.78 \ldots 1.79 ; 1.315) \cdot 10^{-10} \mathrm{~m}$. The portlandite is a weak link cement material to the 
action of corrosion.

According to the peak at $\mathrm{d}=4.93$ we can say that the composition of the modified concrete contains almost 7 times less portlandite than conventional aerated concrete. It is known that soluble substance can leach from the material. Ettringite is a high strength joints in cement systems formed with the participation of gypsum and aluminates. Modified aerated concrete it is formed with the participation of phosphogypsum. With the peak at $\mathrm{d}=9,73$ we can say that the composition of the modified concrete contains 2 times more ettringite than in traditional concrete: -calcium silicate hydrate $-3 \mathrm{CaO} \cdot 2 \mathrm{SiO}_{2} \cdot 3 \mathrm{H}_{2} \mathrm{O}$ with the peak $\mathrm{d}=(6.46 ; 5.74 ; 3.19 ; 2.84 ; 2.74 ; 1.704 ; 1.604) \cdot 10^{-10} \mathrm{~m} ;-$ calcium hydrated ferrite $-3 \mathrm{CaO} \cdot \mathrm{Fe}_{2} \mathrm{O}_{3} \cdot 6 \mathrm{H}_{2} \mathrm{O}$ with the peak $\mathrm{d}=(5.18 ; 4.50 ; 3.402 ; 2.07 ; 1.71) \cdot 10^{-10} \mathrm{~m}$; - calcium hydrated aluminate $-3 \mathrm{CaO} \cdot \mathrm{Al}_{2} \mathrm{O}_{3} \cdot 6 \mathrm{H}_{2} \mathrm{O}$ with the peak $\mathrm{d}=(5.14 ; 4.46 ; 2.3 ; 2.23 ; 2.04$; $1.68 ; 1.60) \cdot 10^{-10} \mathrm{~m}$.

Optimal spatial structure of aerated concrete consists of cement-sand matrix, filled with small pores (less than $0.8 \mathrm{~mm}$ in diameter). The maximum porosity of aerated concrete with a thickness of interporous partitions $80-100$ microns and a pore diameter of $0.8 \mathrm{~mm}$ up to 76 to $83 \%$. The use of complex organic-mineral modifiers of the type of GM in the modified non-autoclave aerated concrete products with man-made waste significantly increases the probability of receiving quality products by controlling the processes of gas evolution and structure formation due to the organic modifier.

From table 1 and figure 1 it is evident that the modified concrete is different from the traditional more developed and uniform porous structure with increased cellular porosity. In this case, the diameter of the cellular pores is less than $0.8 \mathrm{~mm}$, or 800 microns, ie, decreases in 2 times. A reduction in the gel and capillary porosity in 1.5-2 times, which is explained by the positive influence of hydrophobe effect of ion modifier. On the one hand, capillary porosity and porosity at the air entrainment, reduces the frost resistance of saturated concrete. On the other hand, with air entrainment, porosity and multi-porosity with pore sizes larger than $1 \mathrm{~mm}$ increases the conductivity. The heat loss through the walls caused by convection method of heat transfer during the heating season due to the increase of thermal conductivity. Therefore, reduction of the gel and capillary porosity reduces the risks of destruction of concrete walls with alternating freezing and thawing. The diameter reduction of cellular porosity reduces the heat loss through the walls.

\section{Conclusion}

Analysis of the results shows that the application of the modified non-autoclaved aerated concrete based on industrial wastes will provide environmental security by significantly reducing heat loss through the walls of buildings in the formation of cracks under the action of frost and inhomogeneous pore structure of traditional concrete. Environmental safety will be improved due to saving of energy for heating of residential premises and due to reduce release of heat into the atmosphere. The removal of heat in the atmosphere, as is known, contributes to the greenhouse effect. Moreover, the environmental safety of buildings and the environment is impossible without reliable operation walling - concrete wall blocks. X-ray diffraction peak at the $\mathrm{C} 3 \mathrm{~S}$ evaluated the degree of hydration of cement: modified aerated concrete as $91 \%$, while the traditional concrete composition $-67 \%$. This is also confirmed by the peak of quartz, which is $40 \%$ lower than that of conventional composition. The use of technogenic wastes in a modified aerated concrete and organicmineral modifier allowed 7 times to reduce the amount of soluble and susceptible to corrosion portlandite compared to traditional concrete. 2 times increases the amount of ettringite. 
Therefore, recycling of technogenic wastes in a modified aerated concrete and organicmineral modifier significantly increases the environmental safety of the environment due to the hardening of the structure, increasing its uniformity and thermal properties.

\section{References}

1. S.A. Tkach, V.I. Telichenko, Ecology of urbanized territories in Moscow 2, 39-44 (2016)

2. V.I. Telichenko, D.V. Oreshkin, Ecology of urbanized areas 2, 31-33 (2015)

3. D.V. Oreshkin, Building materials 11, 6-8 (2010)

4. D.V. Oreshkin, O.B. Lyapidevskaya, K.I. Kirillov, Construction of oil and gas wells on land and at sea 10, 41-46 (2006)

5. E.V. Tkach, S.A. Tkach, R.F. Serova, E.A. Stasilovich, Modern problems of science and education 1-2, 83-88 (2015)

6. D.V. Oreshkin, Building materials 11, 6-8 (2010)

7. E. Tkach, Procedia Engineering 153, 761-765 (2016)

8. A.V. Sumin, V.V. Strokova, V.V. Nelyubova, S.A. Eremenko, Building materials 1-2, 70-75 (2016)

9. B.M. Rumyantsev, A.D. Zhukov, D.I. Aristov, Scientific review 13, 128-131 (2015)

10. Yu.M. Bazhenov, L.A. Alimov, V.V. Voronin, Vestnik MGSU, 204-210 (2013) 